\title{
UN ENSAYO ACTUAL DE GÉNERO HISTÓRICO
}

\author{
CARLos Moreno HeRnÁndeZ \\ Universidad de Valladolid
}

La publicación en 1998 de cuatro nuevos 'dramas históricos' de Amancio Labandeira, dos de los cuales anunciábamos ya en nuestra reseña a los tres primeros del autor ${ }^{1}$, completa un ciclo textual dedicado a los avatares de la conquista española de los actuales Estados Unidos de América constituye un conjunto insólito y curioso en la bibliografía española actual.

Aquellas tres primeras obras, en edición bilingüe inglés-español, encajaban muy bien en las polémicas surgidas con motivo de la conmemoración del quinto centenario del descubrimiento. El argumento de cada una de las piezas, detallado por Stelio Cro en su prólogo. proporcionaba informaciones adicionales y explicaciones acerca del contexto en el que se desarrollan los hechos. La bibliografía final, recopilada por Silvia Hilton, iba mucho más allá de una guía orientativa para estudiantes de lengua y cultura españolas a uno y otro lado del Atlántico, siendo de especial utilidad para los que viven en un contexto de habla inglesa con una importante minoría hispánica.

La primera de aquellas piezas, Una espada española en Florida, incide en el tema de las rivalidades internacionales en la colonización de América, centrándose en la figura de Pedro Menéndez de Avilés. Sin pretender justificar las actuaciones de unos y otros, desarrolla los móviles interesados de los bandos en conflicto, las coronas española y francesa, envueltas a mediados del siglo XVI en sus particulares guerras de religión, y las rivalidades frente a ellas de las tribus indígenas, lejos de las idealizaciones que, desde el 'buen salvaje' dieciochesco en una sociedad natural no co-

1 Amancio LABANDEIRA, Españoles en norteamérica: cuatro dramas. Madrid: Comunidad de Madrid, 1998. Para la edición anterior, véase: Amancio LABANDEIRA, Spaniards in North America:Three Plays, bilingual edition, translated with an introduction and notes by Stellio and Ann Cro. Bibliografía selecta by Sylvia L. Hilton, Tallahassee, Florida: De Soto Press, 1991; y nuestra reseña: "Españoles en norteamérica: Historia, literatura, drama", en CELEHIS. Revista del Centro de Letras Hispanoamericanas. Mar del Plata, 4-5 (1995) 233-241. 
rrompida conducen a su actual consideración de meros explotados y esclavizados. Los europeos no hacen sino trasladar sus conflictos al nuevo continente y Menéndez se comporta como lo hacían los católicos franceses contra los hugonotes en su país, que es lo mismo que decir los católicos en general contra la reforma protestante, como queda claramente explicado en su entrevista con Ribault en el acto II (pp. 92 ss.). A la larga, serán los defensores ingleses de la reforma los que dominen en la 'Florida', esto es, en la costa este norteamericana, frente a los más 'anticuados' católicos. El inicial conflicto de Menéndez con sus misioneros, al reprocharle éstos su crueldad con los franceses, se invierte en el acto tercero: la religión no es más que el pretexto de unos y otros para obtener tierras y poder para sus respectivas coronas, pues la ejecución de los franceses puede interpretarse dentro del plan de Menéndez de descubrir la traición indígena revelada al final y que explica las confidencias anteriores, introduciendo el otro enemigo, tercero en la discordia.

La segunda obra en edición bilingüe, La cuestión de Nueva Orleans, se sitúa en el contexto de la Ilustración dieciochesca y sus ideas de tolerancia, encarnadas en el gobernador Ulloa, expulsado por los colonos franceses de la Luisiana por su supuesta ineptitud; en el fondo, como antes, está el conflicto entre las coronas europeas por el dominio militar y político de Norteamérica, junto con el deseo de los colonos de emanciparse de ellas. No hay indios ni misioneros aquí y dominan los aspectos económicos y políticos, ligados al dominio militar. La obra presenta anticipadamente, concentrado a pequeña escala, el conflicto paralelo en Europa y América entre la monarquía absoluta y los deseos de emancipación y revolución. El utópico Ulloa cede el paso al militar O'Reilly, mercenario de la corona española, quien aplasta la sublevación. El despotismo ilustrado revela su fracaso por anticipado en un nuevo continente donde queda más claro que las nuevas ideas son incompatibles con las viejas estructuras. Pero los colonos tampoco salen bien parados: sus intereses egoístas intentan enmascararse en una hipócrita adhesión patriótica.

La tercera obra, De San Diego a Monterrey, es la más larga e interesante, pues plantea agudamente, en el marco de la exploración y conquista de la Alta California, la colisión entre los intereses de la corona bajo la Ilustración, los criollos mejicanos y los misioneros franciscanos que han venido a sustituir en América a los jesuitas expulsados por el rey Carlos III; y todo ello bajo la amenaza creciente de la colonización inglesa y rusa. El conflicto entre Gaspar de Portolá, jefe de la expedición que debe confirmar la existencia del puerto de Monterrey y asentarse en él, y Fernando de Rivera, el capitán criollo con hermano jesuita, queda muy bien explicado en el diálogo entre ambos sobre el gobierno y la administración colonial de los Borbones en el acto II (pp. 356 ss.): los criollos quieren la equiparación total con los peninsulares o, de lo contrario, dice Rivera (364) 
se acelerará la segregación de la metrópoli, anunciada ya en las protestas que siguieron a la expulsión de los jesuitas. No obstante, ambos están de acuerdo en que el poder eclesiástico no debe interferir en el civil, lo que queda reflejado en las continuas divergencias de los militares con los franciscanos dirigidos por Fray Junípero Serra, empeñados en una utópica evangelización pacífica sin trabas por parte de la Corona.

No falta en esta obra la nota sentimental, con el pretendido matrimonio entre el teniente Pedro Fagés y la india doña María, y las trabas oficiales para llevarlo a cabo, lo que sirve de marco para introducir información sobre la lengua y cultura de los indios californianos; pero las trabas oficiales no son lo único que se interpone entre los amantes y provoca su separación: las supersticiones indias también intervienen, y el círculo de intereses queda cerrado al final de la obra con la narración en off del reencuentro de los amantes y de su muerte.

Los cuatro dramas históricos de Labandeira publicados en 1998 vienen a completar los anteriores. El primero, titulado Acoma: españoles entre mitos y traiciones, trata de la entrada de Juan de Oñate en Nuevo Méjico en el año de 1599; en ella se recoge el deseo de este capitán por descubrir el estrecho de Anián, que comunicaría Atlántico y Pacífico, y el fabuloso reino de Quivira. A lo largo de la acción de la obra queda patente la crueldad de Oñate y de los conquistadores españoles.

El segundo, El otro informe del fuerte San Diego, continúa con el tema de la conquista y evangelización de la Alta California durante el último tercio del siglo XVIII que ya había tratado en su obra anterior De San Diego a Monterrey, esta vez incidiendo más en el tema de las relaciones con los indígenas y los conflictos entre los militares y los religiosos franciscanos respecto a ellas.

El tercero, Un marino español espera en Nutka, dramatiza los problemas surgidos entre la expedición naval al mando del capitán Esteban Martínez — quien, en 1789, se asentó en la pequeña isla de Nutka, muy cercana a la de Vancouver-, y las compañías peleteras inglesas y rusas que pretendían hacer de esta isla el centro americano de su comercio con China.

El cuarto, Todos, todos vienen hacia San Antonio, trata de la primera rebelión de los criollos mejicanos de Tejas contra los realistas españoles tras la revolución fallida de Miguel Hidalgo, cuando ya se presiente la amenaza de los angloamericanos de la Unión que acabarían por apoderarse del territorio. La maraña de fuerzas en conflicto se complica con los sórdidos intereses personales hasta derivar en un interrogante final sobre el futuro de Tejas. 
Las siete obras publicadas hasta la fecha por Labandeira ofrecen una visión de conjunto muy completa de los avatares de los españoles en Norteamérica en la época colonial, de este a oeste, desde Florida a California, pasando por Luisiana, y de norte a sur, desde el actual Vancouver hasta Tejas y Nuevo Méjico.

$\mathrm{Al}$ igual que los tres primeros ya reseñados, los cuatro nuevos dramas históricos tienen una estructura clásica, con tres actos que siguen la ley de las tres unidades y se concentran en una acción particular y en unos personajes particulares representantes de fuerzas de la época en conflicto. Con este planteamiento, el autor intenta explicar, más que justificar, unos comportamientos en unas situaciones determinadas, sin otros juicios de valor que los que se derivan de actos dictados por los intereses políticos o por los meramente personales disfrazados de los otros.

No podemos dejar de insistir en lo que ya decíamos anteriormente sobre las tres primeras obras de Labandeira, cercanas en su planteamiento a los dramas históricos de Schiller tal como son justificados por Dilthey, para quien la metodología histórica no basta para captar la realidad histórica en toda su complejidad; de ahí la necesidad de que la literatura le sirva de complemento y se ocupe de esa realidad en cuanto temple espiritual de una época, conflicto humano plasmado en un drama o novela. Y cada época se rige por unos valores que le son propios, lo que confiere a los móviles de los personajes una justificación según el contexto, dejando al lector que juzgue sobre lo que hay de censurable en ellos en su ambición personal desmedida, crueldad o mera estupidez.

También quedan en evidencia a menudo las contradicciones de los conquistadores en relación con su marco de valores. Véase, como muestra, el final de El otro informe de el fuerte San Diego, cuando Diego, el indígena californiano, le dice a Ortega:

Primero nos quieren formar como personas perfectas y después nos hostigan si no caemos en los vicios más comunes. Aquí siempre ocurrirá lo mismo; nunca pasará nada nuevo; todo seguirá siempre igual; y por ello me refugio en la dignidad que es lo último que me queda. (163-4)

Por otra parte, las obras de Labandeira - y es este otro de sus méritos- están basadas en una rigurosa documentación que cualquier conocedor de la historia norteamericana puede comprobar. En la anterior edición se nos proporcionaban las fuentes bibliográficas, a las que remitimos al lector curioso y sin duda muy gratamente impresionado por la sabia armonización entre ingredientes que el autor ha sabido llevar a sus dramas.

Así pues, la actualidad de estas obras estribaría en buena parte en conjugar la presentación dramática con la investigación histórica. La separación entre Historia, en tanto discurso que pretende un saber o verdad ob- 
jetivos, y Literatura, en cuanto discurso ficticio, es producto de la ilustración dieciochesca que se afianza en el siglo XIX con el avance de las pretensiones científicas de la Historia. De ahí que para Georg Lukàcs ${ }^{2}$ y sus presupuestos, el materialismo histórico y el realismo socialista, la novela histórica, en cuanto representación libre o artística de un período histórico concreto y su singularidad determinante de la actuación de unos personajes, en general ficticios, surge precisamente con el Waverley de Scott (1814). Así mismo, el drama histórico 'renace' con la Ilustración alemana (el Götz, de Goethe o los dramas de Schiller) y su influencia en la aparición de la novela histórica es fundamental, pues en Alemania ese renacimiento se produce por la necesidad de profundizar en las causas de la ruina y la decadencia del país, mirando al pasado.

Además, la revolución francesa y las guerras napoleónicas, según Lukàcs, convierten a la historia en una experiencia de masas de proporciones europeas. Entre 1789 y 1814 se adquiere conciencia de una serie de cambios sociales y de su carácter propiamente histórico, esto es, no natural. Para Lukàcs, siguiendo a Hegel, lo que distingue el drama histórico de la novela histórica es la concentración en una acción particular y unos personajes particulares, en un efecto concreto de choque; todo está, a la vez, simplificado y generalizado en una gran colisión (110). Lukàcs formula la teoría del reflejo aplicada al drama histórico de la siguiente manera:

la colisión social exige la plasmación de hombres que en sus pasiones personales representen en forma inmediata las fuerzas cuyo choque constituye el contenido objetivo de la colisión (122)

y cita a Manzoni (124), para quien la teoría de las tres unidades no hace más que exagerar, deformándola, la idea de colisión concentrada del drama, aunque tenga su justificación histórica.

En el drama, a diferencia de la épica y la novela, desaparecen todas aquellas manifestaciones de la vida que no guardan una relación inmediata con los hechos vitales que producen la 'colisión' y que ocupan el centro en torno al cual se agrupa todo, hechos que sólo aparecen bajo determinadas condiciones histórico-sociales (125). Sin embargo, esta distinción no deja de ser relativa, en función del punto de vista, de la densidad narrativa y de otros recursos estudiados por la narratología.

Por otra parte, es evidente el contraste entre el optimismo de Lukàcs y el pesimismo del actual fin de siglo. En este aspecto, creemos que las obras de Labandeira podrían inscribirse en la puesta en duda del sentido progresista o teleológico de la Historia prevaleciente desde el siglo XIX hasta la crisis de las concepciones marxistas. Labandeira contextualiza sus obras con

2 Georg LUKÀCS, La novela histórica. México: Era, 1961 
amplio apoyo bibliográfico para explicar, más que justificar, unos comportamientos en unas situaciones determinadas, sin búsqueda alguna de aplicación o moraleja en relación al presente y sin juicios de valor sobre ellos.

A la vez, las obras de Labandeira ejemplificarían perfectamente la idea, también decimonónica, de Giner de los Ríos y los institucionistas, de la obra literaria como medio educativo para enseñar y entender la Historia. Dice Giner en 1862, en sus 'Consideraciones sobre el desarrollo de la literatura moderna':

no es otra cosa la literatura que el primero y más firme camino para entender la historia realizada (...) Suprímase la literatura de un pueblo y en vano se apelará para reconstituir su pasado a su historia política, muda armazón de sucesos, esqueleto que no reviste la virilidad de la musculatura ni anima el vivificante calor de la sangre.

Hemos indicado ya que las obras de Labandeira tienen una estructuración análoga de raigambre clásica: tres actos que siguen, grosso modo, la ley de las tres unidades. En el primer acto predomina la narración retrospectiva que sitúa al lector o espectador en la problemática en torno al conflicto de fuerzas o colisión fundamental que constituye la unidad de acción de cada una de las piezas. Dicha narración incluye todo tipo de detalles que remiten, sin decirlo, a las fuentes históricas. Se produce así un aporte informativo riguroso encarnado en unos personajes que han vivido lo que cuentan.

Cabría objetar, quizás, que la representación escénica de un diálogo como éste, cargado de continuas referencias al pasado, podría resultar monótona, o que el espectador podría perderse fácilmente ante el cúmulo de detalles, fechas y personajes a los que se alude y que no aparecen en escena, pero creemos que este elemento informativo, o didáctico, está bien dosificado. Si la lectura es siempre entretenida, su puesta en escena puede serlo también y más aún, tal vez, su adaptación como guión cinematográfico.

Por otra parte, hemos apuntado también al principio de esta nota la sugerencia de que las obras de Labandeira están más cerca de la concepción del drama histórico elaborada por Dilthey ${ }^{3}$ a propósito de Schiller. Para Dilthey, el drama histórico se justifica por la relación entre ciencia histórica y realidad histórica, pues no hay correspondencia, no es la primera un reflejo veraz de la segunda y de ahí la posibilidad, o la necesidad, de que la literatura se ocupe de la historia, pues el temple espiritual de una época, dice, no puede captarse objetivamente por medio de ningún procedimiento metódico, sino solamente mediante la fuerza de la visión espiritual, que encierra siempre algo subjetivo. $\mathrm{Y}$ el historiador se convierte en artista cuando consigue esto, que es en gran parte una tarea poética.

3 Wilhem Dilthey, Obras, IV: Vida y Poesía, México: F.C.E., 1953, pp. 219 ss. 
El defecto que Lukàcs (189 ss.) ve en los dramas de Schiller es que, por influencia de la Ilustración, tienden a configurar 'lo humano en general', frente a las particularidades de la sociedad de clase, con lo cual los personajes se apartan a veces de toda realidad histórica y se convierten en portavoces, o 'altavoces', del poeta. El siglo XIX vendría a corregir esto, sobre todo a través de la novela histórica de Scott: las fuerzas motrices político-sociales se transforman en el juego recíproco de individuos concretos antagonistas, quienes, a su vez, son generalizaciones de rasgos histórico-sociales.

Pero Lukàcs (197-8), desde el punto de vista del materialismo histórico, cree que la totalidad del drama debe ser un reflejo adecuado de la regularidad fundamental del devenir histórico, de la necesidad histórica, el proceso que tiende al presente, articulada en personajes adecuados a ella. Su concepción de la historia como devenir coherente, teleológicamente predeterminado, anclada en un evidente determinismo marxista, ha hecho agua en el último tercio del siglo $\mathrm{xx}$ y no es previsible que se recupere.

Por eso, quizás, Labandeira, a la altura de los tiempos en que estamos, ha utilizado una metodología histórica de fondo, proporcionando las fuentes, su crítica y su interpretación. La leyenda negra, como la blanca, está toda ahí, como otras interpretaciones que prevalecen en determinados países o contextos, según intereses y valores: como los que los personajes de las obras debaten, sin que el autor, como señala el prologista, pretenda ocultar sus defectos o glorificar sus acciones. Sus móviles se justifican, o no, en su contexto, de acuerdo con valores distintos a los actuales. A la vez, los valores actuales supuestamente superiores no aparecen tampoco a través de personajes portavoces, no hay tesis más o menos solapada, lo cual no implica que el autor, como los lectores o espectadores, carezcan de valores.

Cuando en nuestros días se separan tan arbitrariamente los estudios históricos y los literarios, estas obras ilustran que toda pretensión científica, como toda obra teatral, histórica o no, está siempre cargada de valores. El problema surge cuando se pretende prescindir de ellos en aras de una objetividad imposible o, al contrario, cuando se airean con pretensión de absolutos para explicarlo o justificarlo todo. 